\title{
The utility of exercise for weight control
}

\begin{abstract}
In August of 2009, TIME magazine created a minor uproar among exercise professionals with their cover story The Myth About Exercise stating that it "... won't make you lose weight". Many of us were quick to point out that if exercise was indeed futile in weight control efforts, obesity prevalence would be greatest among active individuals while sedentary individuals would be those with healthy body weights. Many dietitians, on the other hand, supported TIME's claims, noting that the 'energy in' part of the weight loss equation often influences energy balance to a far greater degree than energy expended. For example, a McDonald's quarter pound bacon and cheeseburger contains about 600 kilocalories. Depending on how hungry (and motivated) you are, it could potentially take you less than 10 minutes to eat this cheeseburger. To expend this energy; however, it may take over an hour of exercise. It is far easier to consume less energy than expend more when weight loss is the goal. This has generally been accepted, although it has also been accepted that exercise is part of the prescription for a healthy body weight. The American College of Sports Medicine has issued recommendations for exercise to induce weight loss and numerous weight loss programs have a physical activity/exercise component. Common knowledge persists that exercise is good for weight loss; although many published research studies are beginning to shed light on the energy balance equation and how exercise can effect energy balance in more ways than we once thought.
\end{abstract}

Volume 7 Issue 3 - 2017

\section{Kyle D Flack}

Department of Dietetics and Human Nutrition, University of Kentucky, USA

\begin{abstract}
Correspondence: Kyle D Flack, Department of Dietetics and Human Nutrition, 206E Funkhouser Building, University of Kentucky, Lexington Kentucky, 40506, USA, Fax 859257435I, Email Kyle.Flack@uky.edu
\end{abstract}

Received: October 06, 2017 | Published: October 12, 2017

Keywords: exercise, weight loss, energy intake, hunger, food reinforcement

Abbreviations: ACSM, american college of sports medicine; GLP1, glucagon-like peptide $1 ; \mathrm{RRV}_{\text {food }}$, relative reinforcing value of food

\section{Introduction}

The general perception amongst Americans is that exercise is a great way to lose weight, $71 \%$ of us to be exact. ${ }^{1}$ As a health professional, I would never refute this or discourage anyone whose goal is to lose weight from engaging in exercise. After all, the American College of Sports Medicine has issued specific recommendations for exercise when weight loss is the primary goal ${ }^{2}$ and some have shown that aerobic exercise by itself results in meaningful weight loss. ${ }^{3,4}$ For weight loss to occur, energy expenditure must exceed energy intake, making it is easy to assume that increasing energy expenditure through exercise would favorably tip this balance towards weight loss. Despite this seemingly simple reasoning, there are just as many studies that show little to no weight loss with exercise. ${ }^{5-8}$ Of course there are many variables that can impact an exercise intervention's success (participant adherence, exercise dose/intensity prescribed, sample population) leading many of us exercise advocates to conclude that weight loss interventions that used exercise and failed were flawed in some way. Although it is becoming more apparent that the relationship between energy intake and expenditure if far more complex, with many other facets contributing to the simple energy in - energy out equation. These include reductions in resting metabolic rate and nonexercise energy expenditure and improved metabolic efficiency as the human body naturally strives to maintain energy balance regardless of the situation. ${ }^{9-12}$ These factors, however, are negligible when compared to the much greater contributor to this equation: increased dietary energy intake. ${ }^{12}$

Many individuals are aware that to achieve weight loss success they will have to, at the very least, pay attention as what they are eating. Individuals who successfully reduce energy intake upon initiating an exercise program often experience the greatest weight loss, where those who fail to monitor their energy intake often compensate for the energy expended through exercise by increasing their intake. ${ }^{10}$ In fact, if one does not deliberately control energy intake, it is very likely they will naturally compensate, at least to some degree, regardless of exercise dose. ${ }^{12,13}$ General reasoning may suggest that exercise makes one feel hungrier, driving individuals to eat more than they would without exercise. Although it seems this isn't always the case, as the general consensus is that acute bouts of exercise do not cause compensatory changes in appetite, food intake, and appetite regulatory hormones. ${ }^{14-16}$ Although my hunch is that the loose coupling that exists between energy balance and energy intake ${ }^{17}$ prevents the detection of these changes when assessed in acute settings. Even studies over the course of 24 or 48 hours investigating hunger, food intake, and appetite regulatory hormones ${ }^{18-20}$ have failed to observe consistent changes with exercise. It is therefore possible that energy intake is spontaneously increased over a period of several days in effort to maintain energy balance. It also may be possible that a factor other than hunger is driving energy intake during periods of exercise-induced negative energy balance. For instance, the hormones ghrelin and glucagon-like peptide 1 (GLP-1) both act on the meso-accumbal dopamine system to play a role in reward-driven feeding ${ }^{21,22}$ and preliminary data has shown these are altered with long-term exercise. The meso-accumbal dopamine system is essential for experiencing appetitive reward and assimilating information about energy balance. ${ }^{23}$ This reward driven feeding is often termed the "relative reinforcing value" of food $\left(\mathrm{RRV}_{\text {food }}\right)^{24,25}$ and is a strong predictor of greater energy intake and body weight. It is very possible that exercise induces food cravings that are separate from hunger. This is often observed anecdotally, as people (especially novice exercisers) often feel the need to "treat" themselves after exercise or feel that since they exercised today they can/should eat that second helping of 
dessert (for example). Even if those exercising don't specifically think about "treating" themselves, it is very possible that they are naturally drawn towards the reinforcing aspects of food- a mechanism the body is using to maintain energy balance.

\section{Conclusion}

A negative energy balance, although needed for weight loss, is perceived as a threat to the body and elicits mechanisms to maintain energy balance. This is problematic for those exercising in effort to lose weight, as the hard work put into expending energy and creating this negative energy balance is concurrently being fought by the human body. One thought is that exercise promotes greater energy intake through increases in hunger, although this is not observed after acute exercise sessions. It is possible that hunger may be driving greater energy intakes with exercise, but slowly. This process of energy compensation may last over a period of several days, with only marginal differences in single meals or across one day. A less studied possibility that may drive energy intake and maintenance of energy balance with exercise is an increase in reward driven feeding. Future research should focus on elucidating these mechanisms and how to structure an exercise program to most favorably attenuate the compensatory response to energy expended during exercise.

\section{Acknowledgements}

Dr. Kyle Flack, RD is an assistant professor in the Department of Dietetics and Human Nutrition the University of Kentucky and would like to thank all of the other faculty, staff, and students in the department who contribute to his research findings.

\section{Conflict of interest}

The author declares no conflict of interest.

\section{References}

1. Thomas DM, Kyle TK, Stanford FC. The gap between expectations and reality of exercise-induced weight loss is associated with discouragement. Prev Med. 2015;81:357-360.

2. Donnelly JE, Blair SN, Jakicic JM, et al. American College of Sports Medicine Position Stand. Appropriate physical activity intervention strategies for weight loss and prevention of weight regain for adults. Med Sci Sports Exerc. 2009;41(2):459-471.

3. Donnelly JE, Honas JJ, Smith BK, et al. Aerobic Exercise Alone Results in Clinically Significant Weight Loss for Men and Women: Midwest Exercise Trial 2. Obesity. 2013;21(3):219E -228E.

4. Ross R, Janssen I, Dawson J, et al. Exercise-induced reduction in obesity and insulin resistance in women: A randomized controlled trial. Obes Res. 2004;12(5):789-798.

5. Church TS, Earnest CP, Thompson AM, et al. Exercise without Weight Loss Does Not Reduce C-Reactive Protein: The INFLAME Study. Med Sci Sports Exerc. 2010;42(4):708-716.

6. Kraus WE, Houmard JA, Duscha BD, et al. Effects of the amount and intensity of exercise on plasma lipoproteins. New Engl J Med. 2002;347(19):1483-1492.

7. Westerterp KR, Meijer GA, Janssen EM, et al. Long-term effect of physical activity on energy balance and body composition. Br J Nutr. 1992;68(1):21-30.
8. Bingham SA, Goldberg GR, Coward WA, et al. The effect of exercise and improved physical fitness on basal metabolic rate. $\mathrm{Br} J$ Nutr. 1989;61(2):155-173.

9. King NA, Hopkins M, Caudwell P, et al. Individual variability following 12 weeks of supervised exercise: identification and characterization of compensation for exercise-induced weight loss. Int J Obes (Lond). 2008;32(1):177-184.

10. Leibel RL, Rosenbaum M, Hirsch J. Changes in energy expenditure resulting from altered body weight. $N$ Engl J Med. 1995;332(10):621628 .

11. Thomas DM, Bouchard C, Church T, et al. Why do individuals not lose more weight from an exercise intervention at a defined dose? An energy balance analysis. Obes Rev. 2012;13(10):835-847.

12. Rosenkilde M, Auerbach P, Reichkendler MH, et al. Body fat loss and compensatory mechanisms in response to different doses of aerobic exercise - a randomized controlled trial in overweight sedentary males. American journal of physiology. Regulatory, integrative and comparative physiology. 2012;303(6):571R-579R.

13. King JA, Wasse LK, Stensel DJ. Acute exercise increases feeding latency in healthy normal weight young males but does not alter energy intake. Appetite. 2013;61(1):45-51.

14. King NA, Burley VJ, Blundell JE. Exercise-induced suppression of appetite: effects on food intake and implications for energy balance. Eur J Clin Nutr. 1994;48(10):715-724.

15. Schubert MM, Desbrow B, Sabapathy S, et al. Acute exercise and subsequent energy intake. A meta-analysis. Appetite. 2013;63:92-104.

16. Blundell JE, King NA. Effects of exercise on appetite control: loose coupling between energy expenditure and energy intake. Int J Obes Relat Metab Disord. 1998;22(Suppl 2):22S-29S.

17. Beaulieu K, Olver TD, Abbott KC, et al. Energy intake over 2 days is unaffected by acute sprint interval exercise despite increased appetite and energy expenditure. Appl Physiol Nutr Metab. 2015;40(1):79-86.

18. Douglas JA, King JA, McFarlane E, et al. Appetite, appetite hormone and energy intake responses to two consecutive days of aerobic exercise in healthy young men. Appetite. 2015;92:57-65.

19. Heden TD, Liu Y, Park Y, et al. Acute aerobic exercise differentially alters acylated ghrelin and perceived fullness in normal-weight and obese individuals. J Appl Physiol (1985). 2013;115(5):680-687.

20. Skibicka KP. The central GLP-1: implications for food and drug reward. Front Neurosci. 2013;7:181.

21. Naleid AM, Grace MK, Cummings DE, et al. Ghrelin induces feeding in the mesolimbic reward pathway between the ventral tegmental area and the nucleus accumbens. Peptides. 2005;26(11):2274-2279.

22. Charlotte Huppertz, Meike Bartels, Maria M, et al. The dopaminergic reward system and leisure time exercise behavior: a candidate allele study. BioMed research international. 2014;2014:591717.

23. Epstein LH, Leddy JJ, Temple JL, et al. Food reinforcement and eating: a multilevel analysis. Psychological bulletin. 2007;133(5):884-906.

24. Epstein LH, Truesdale R, Wojcik A, et al. Effects of deprivation on hedonics and reinforcing value of food. Physiol Behav. 2003;78(2):221227.

25. Epstein LH, Carr KA, Lin H, et al. Food reinforcement, energy intake, and macronutrient choice. Am J Clin Nutr. 2011;94(1):12-18. 